\title{
Experiments and Simulations of Laminar Forced Convection With Water-Alumina Nanofluids in Circular Tubes
}

Ivana G. Cerqueira , Carlos Alberto A. Mota , Jeziel S. Nunes, Renato M. Cotta , Andrea Balbo \& Carlos A. Achete

To cite this article: Ivana G. Cerqueira, Carlos Alberto A. Mota, Jeziel S. Nunes, Renato M. Cotta , Andrea Balbo \& Carlos A. Achete (2013) Experiments and Simulations of Laminar Forced Convection With Water-Alumina Nanofluids in Circular Tubes, Heat Transfer Engineering, 34:5-6, 447-459, DOI: $10.1080 / 01457632.2012 .722433$

To link to this article: https://doi.org/10.1080/01457632.2012.722433

Accepted author version posted online: 04

Sep 2012.

Published online: 04 Sep 2012.

Submit your article to this journal $2 \pi$

山ll Article views: 259

Citing articles: 4 View citing articles 


\title{
Experiments and Simulations of Laminar Forced Convection With Water-Alumina Nanofluids in Circular Tubes
}

\author{
IVANA G. CERQUEIRA, ${ }^{1}$ CARLOS ALBERTO A. MOTA, ${ }^{2}$ JEZIEL S. NUNES, ${ }^{3}$ \\ RENATO M. COTTA, ${ }^{1}$ ANDREA BALBO,${ }^{4}$ and CARLOS A. ACHETE ${ }^{5}$ \\ ${ }^{1}$ Laboratory of Transmission and Technology of Heat-LTTC, Department of Mechanical Engineering, Federal University \\ of Rio de Janeiro, Rio de Janeiro, Brazil \\ ${ }^{2}$ National Council of Science and Technology-CNPq, Brasilia, Brazil \\ ${ }^{3}$ National Institute of Industrial Property-INPI, Rio de Janeiro, Brazil \\ ${ }^{4}$ Corrosion and Metallurgy Study Centre “Aldo Daccò,” Engineering Department, University of Ferrara, Ferrara, Italy \\ ${ }^{5}$ INMETRO, National Institute of Metrology, Standardization and Industrial Quality, Rio de Janeiro, Brazil
}

\begin{abstract}
This work reports fundamental experimental-theoretical research related to heat transfer enhancement in laminar channel flow with nanofluids, which are essentially modifications of the base fluid with the dispersion of metal oxide nanoparticles. The nanofluids were synthesized by a two-step approach, using a dispersant and an ultrasound probe or a ball mill for alumina nanoparticles dispersion within the aqueous media. The theoretical work involves the proposition of an extension of the thermally developing flow model that accounts for the temperature variation of all the thermophysical properties, including viscosity and the consequent variation of the velocity profiles along the thermal entry region. The simulation was performed by making use of mixed symbolic-numerical computation on the Mathematica 7.0 platform and a hybrid numerical-analytical methodology (generalized integral transform technique, GITT) in accurately handling the governing partial differential equations for the heat and fluid flow problem formulation with temperature dependency in the thermophysical properties. Experimental work was also undertaken based on a thermohydraulic circuit built for this purpose, and sample results are presented to verify the proposed model. The aim is to confirm that both the constant properties and temperature-dependent properties models, besides available correlations previously established for ordinary fluids, provide adequate prediction of the heat transfer enhancement observed in laminar forced convection with such nanofluids and within the experimented Reynolds number range.
\end{abstract}

\section{INTRODUCTION}

Nanotechnology has been providing great opportunities in thermal engineering development, such as achieved with the

The authors acknowledge the financial support provided by $\mathrm{CNPq}$ and FAPERJ, Brazil. This work was partially supported by the Petrobras Research Center (CENPES-PETROBRAS S.A.), through project PEM 7393, COPPETEC Foundation, Rio de Janeiro, Brazil. The authors are grateful to Dr. Fernando V. Castellões, from Cenpes/Petrobras, manager and supporter of the present research effort.

Address correspondence to Professor Renato M. Cotta, Laboratory of Transmission and Technology of Heat-LTTC, Department of Mechanical Engineering, Federal University of Rio de Janeiro, POLI \& COPPE/UFRJ, Rio de Janeiro, RJ, Brazil.E-mail: cotta@mecanica.coppe.ufrj.br capacity of processing and producing materials with average sizes below $50 \mathrm{~nm}$. Recognizing an opportunity to apply this emerging nanotechnology to thermal engineering, it has been proposed [1] that nanometer-sized metallic or metal oxide particles be suspended in industrial heat transfer fluids, such as water, ethylene glycol, or engine oil, to produce a new class of engineered fluids with higher thermal conductivity. The authors coined the term nanofluid for this new class of heat transfer fluids [2]. A number of experiments on nanofluids have indicated significant increases in thermal conductivity compared with liquids without nanoparticles or larger particles, and strong temperature dependence of thermal conductivity [3-5].

The literature already reports some applications of nanofluids directly in the energy sector, as in the case of power transformers 
and hybrid systems for air conditioning. However, it is still necessary to consolidate the fundamental analysis on convective heat transfer with nanofluids, especially with respect to the variation of thermophysical properties with temperature, to enable the adequate choice of simulation or correlation tools in order to achieve proper design of heat transfer equipment with nanofluids. For this reason, a number of contributions have been recently aimed at understanding both experimentally and theoretically the convective behavior of nanofluids, as reviewed in different sources [6-9]. A few recent studies were identified [10-18] that provide some insight on the influence of the temperature-dependent thermophysical properties as well as on the covalidation of simulations, correlations, and experiments.

Nanofluids were here produced with nanoparticles of alumina $\left(\mathrm{Al}_{2} \mathrm{O}_{3}\right)$ dispersed in ultrapure water, and the major physical properties were compared with those obtained for the base fluid [19]. The properties measured were the thermal conductivity, thermal diffusivity, viscosity, and density. Standard ASTM methods were used in order to measure these properties, such as the Flash method, line heat-source probe, and rotational viscometer [20]. Due to the particular relevance of thermal conductivity values in heat transfer enhancement studies, two different approaches were adopted for identification of this thermophysical property and were critically compared [20].

The present contribution then summarizes the comparisons between experiments and simulations of laminar forced convection with the synthesized water-alumina nanofluids, trying to focus on the fundamental aspects that are required to play some role in matching the classical heat transfer models and correlations to the produced experimental results. Emphasis is here placed on the effect of the temperature dependence of the measured thermophysical properties on simulations in laminar convective heat transfer with nanofluids, since the classical heat transfer coefficient correlations have been supposed to fail in predicting the nanofluids behavior with their effective thermophysical properties.

All the theoretical work was performed by making use of mixed symbolic-numerical computation via the Mathematica 7.0 platform [21], and a hybrid numerical-analytical methodology with automatic error control, the generalized integral transform technique (GITT) [22-25], in handling the governing nonlinear partial differential equations. Experimental work was also undertaken through a built and tested thermohydraulic circuit, and sample results are briefly discussed and presented to verify the proposed model and available correlations for heat transfer coefficients in laminar tube flow. The proposed extended thermally developing flow model accounts for the temperature dependence in all the thermophysical properties [26], starting from a fully developed flow at the duct entrance. Since viscosity is also considered to vary with temperature, the velocity components are to be determined along the longitudinal coordinate, and are computed by direct integration from the longitudinal momentum equation by neglecting the effect of inertia terms $[27,28]$.

\section{PROBLEM FORMULATION AND SOLUTION METHODOLOGY}

The main concern here is the possible increase of the heat transfer coefficient in internal laminar flows, as a consequence of passive techniques such as solid additives (nanofluids). Thus, forced convection heat transfer inside a circular tube is considered, for incompressible laminar flow of a Newtonian liquid with temperature-dependent thermophysical properties, including viscosity, thermal capacitance, and thermal conductivity. The flow is fully developed at the channel entrance, but the variable viscosity alters the velocity field within the thermal section. The tube is subjected to a prescribed uniform wall heat flux, with uniform inlet temperature and negligible viscous dissipation effects. This problem has a strong practical motivation [26], with a renewed interest due to more recent applications in forced convection with nanofluids. The related energy equation and inlet and boundary conditions are written as [19, 25]:

$$
\begin{gathered}
\rho(T) c_{p}(T)\left[u(r, z, T) \frac{\partial T(r, z)}{\partial z}+v(r, z, T) \frac{\partial T(r, z)}{\partial r}\right] \\
=\frac{1}{r} \frac{\partial}{\partial r}\left[r k(T) \frac{\partial T(r, z)}{\partial r}\right], 0<r<r_{w}, z>0
\end{gathered}
$$

where one may in principle neglect the transversal convective term and the temperature-dependent longitudinal velocity component is obtained by direct integration of the longitudinal momentum equation $[27,28]$ :

$$
\begin{aligned}
& \frac{1}{r} \frac{\partial}{\partial r}\left[r \mu(T) \frac{\partial u(r, z)}{\partial r}\right]=\frac{d p(z)}{d z}, 0<r<r_{w}, z>0(2 \mathrm{a}) \\
& \frac{\partial u(r, z)}{\partial r}=0, r=0, \quad u(r, z)=0, r=r_{w}, z>0
\end{aligned}
$$

The following dimensionless groups are then defined:

$$
\begin{gathered}
R=\frac{r}{r_{w}}, \quad Z=\frac{\alpha_{0} z}{u_{0} r_{w}^{2}}, \quad U(R, Z)=\frac{u(r, z)}{u_{0}} \\
U_{f \mathrm{~d}}(R)=\frac{u_{f \mathrm{~d}}(r)}{u_{0}}=2\left(1-R^{2}\right), \gamma(\theta)=\frac{k(T)}{k_{0}}, \alpha_{0}=\frac{k_{0}}{\rho_{0} c_{p, 0}}, \\
C(\theta)=\frac{\rho_{0} c_{p, 0} u_{f \mathrm{~d}}(r)}{\rho(T) c_{p}(T) u(r, z, T)}, \quad \theta(R, Z)=\frac{T(r, z)-T_{0}}{q_{w} r_{w} / k_{0}}
\end{gathered}
$$

where $R$ and $Z$ are the dimensionless radial and longitudinal coordinates, $U$ is the dimensionless longitudinal velocity component, $U_{f d}$ is the dimensionless fully developed velocity profile at the channel entry, $\gamma$ is the dimensionless thermal conductivity, 
$\alpha_{0}$ is the fluid thermal diffusivity at the entry temperature, $C$ is the dimensionless product of the thermal capacitance and velocity, and $\theta$ is the dimensionless temperature field. The problem formulation in dimensionless form is given as

$$
\begin{gathered}
R U_{f \mathrm{~d}}(R) \frac{\partial \theta(R, Z)}{\partial Z}=C(\theta) \frac{\partial}{\partial R}\left[R \gamma(\theta) \frac{\partial \theta(R, Z)}{\partial R}\right] \\
0<R<1, \quad Z>0 \\
\theta(R, 0)=0, \quad 0 \leq R \leq 1 \\
\frac{\partial \theta(R, Z)}{\partial R}=0, \quad R=0, \quad \gamma(\theta) \frac{\partial \theta(R, Z)}{\partial R}=1 \\
R=1, \quad Z>0
\end{gathered}
$$

where for computational purposes, as is made more clear in the next section, the nonlinear behavior of the velocity component is moved to the right-hand side of Eq. (4a), and only the fully developed velocity profile at the channel entrance is kept at the left-hand side.

An accurate solution of the nonlinear problem (4) is sought, with automatic global error control, employing the generalized integral transform technique (GITT) [22-25]. In applying this hybrid numerical-analytical approach to the present nonlinear nonhomogeneous problem formulation, as in Eqs. (4a)-(4d), it is convenient to propose an analytical filtering solution that may reduce the importance of the source term in boundary condition (4d), that otherwise could noticeably affect the eigenfunction expansion convergence rate. The following simple filtering solution is then proposed:

$$
\theta_{f}(R)=\frac{R^{2}}{2}
$$

with

$$
\theta(R, Z)=\theta^{*}(R, Z)+\theta_{f}(R)
$$

Then the problem formulation becomes:

$$
\begin{gathered}
R U_{f \mathrm{~d}}(R) \frac{\partial \theta^{*}(R, Z)}{\partial Z}=C(\theta) \frac{\partial}{\partial R}\left[R \gamma(\theta) \frac{\partial \theta^{*}}{\partial R}\right]+P_{f}\left(\theta^{*}\right) \\
0<R<1, \quad Z>0 \\
\theta^{*}(R, 0)=-\frac{R^{2}}{2}, \quad 0 \leq R \leq 1 \\
\frac{\partial \theta^{*}(R, Z)}{\partial R}=0, \quad R=0 \quad \frac{\partial \theta^{*}(R, Z)}{\partial R}=\left(\frac{1}{\gamma(\theta)}-1\right) \\
R=1, \quad Z>0
\end{gathered}
$$

where the resulting nonlinear filtered source term becomes

$$
P_{f}\left(\theta^{*}\right)=C(\theta)\left[2 R \gamma(\theta)+R^{2} \frac{\partial \gamma}{\partial \theta}\left(\frac{\partial \theta^{*}}{\partial R}+R\right)\right]
$$

The auxiliary problem is chosen as:

$$
\begin{aligned}
& \frac{d}{d R}\left[R \frac{d \psi_{i}(R)}{d R}\right]+\beta_{i}^{2} R \psi_{i}(R)=0, \quad 0<R<1 \\
& \frac{d \psi_{i}(R)}{d R}=0, \quad R=0 ; \frac{d \psi_{i}(R)}{d R}=0, \quad R=1
\end{aligned}
$$

which yields the solution for eigenfunctions and eigenvalues in terms of Bessel functions as

$$
\psi_{i}(R)=J_{0}\left(\beta_{i} R\right), \quad J_{1}\left(\beta_{i}\right)=0, \quad i=0,1,2, \ldots
$$

where $\mu_{0}=0$ is also an eigenvalue, and the normalization integral is given by

$$
N_{i}=\frac{1}{2} J_{0}^{2}\left(\beta_{i}\right)
$$

while the normalized eigenfunctions result in

$$
\tilde{\psi}_{i}(R)=\sqrt{2} \frac{J_{0}\left(\beta_{i} R\right)}{J_{0}\left(\beta_{i}\right)}
$$

The integral transform pair is then given by:

$$
\begin{aligned}
\theta^{*}(R, Z) & =\sum_{i=0}^{\infty} \tilde{\Psi}_{i}(R) \bar{\theta}_{i}(Z), \quad \text { inverse } \\
\bar{\theta}_{i}(z) & =\int_{0}^{1} R \tilde{\Psi}_{i}(R) \theta^{*}(R, Z) d R, \quad \text { transform }
\end{aligned}
$$

The integral transformation process leads to the following ODE system:

$$
\begin{array}{r}
\sum_{j=1}^{\infty} a_{i, j} \frac{d \bar{\theta}_{j}(Z)}{d Z}=\hat{\bar{h}}_{i}\left(Z, \bar{\theta}_{l}\right), \quad Z>0, \\
i, j, l=0,1,2, \ldots
\end{array}
$$

$$
\bar{\theta}_{i}(0)=\bar{f}_{i}
$$

where the right-hand side vector is formed by the three contributions here:

$$
\begin{aligned}
\bar{h}_{i}\left(Z, \bar{\theta}_{l}\right)= & \hat{\bar{h}}_{i}^{*}\left(Z, \bar{\theta}_{l}\right)+\hat{\bar{q}}_{i}^{*}\left(Z, \bar{\theta}_{l}\right)+\hat{\bar{g}}_{i}^{*}\left(Z, \bar{\theta}_{l}\right) \\
\hat{\bar{h}}_{i}^{*}\left(Z, \bar{\theta}_{l}\right)= & \int_{0}^{1}[C(\theta)-1] \frac{\partial}{\partial R} \\
& \times\left(R \gamma(\theta)\left(\frac{\partial \theta^{*}}{\partial R}+R\right)\right) \tilde{\psi}_{i}(R) d R \\
\hat{\bar{q}}_{i}^{*}\left(Z, \bar{\theta}_{l}\right)= & \int_{0}^{1}\left[\frac{\partial}{\partial R}\left(R \gamma(\theta)\left(\frac{\partial \tilde{\psi}_{i}(R)}{\partial R}\right)\right)\right] \\
& \times\left[\theta^{*}(R, Z)+\frac{R^{2}}{2}\right] d R \\
\hat{\bar{g}}_{i}\left(Z, \bar{\theta}_{j}\right)= & \tilde{\psi}_{i}(1)
\end{aligned}
$$


and

$$
\frac{\partial \gamma(\theta)}{\partial R}=\frac{\partial \gamma(\theta)}{\partial \theta} \frac{\partial \theta}{\partial R}
$$

or in terms of the more detailed expressions

$$
\begin{aligned}
\hat{q}_{i}\left(Z, \bar{\theta}_{j}\right)= & \int_{0}^{1}\left[R\left(\theta^{*}(R, Z)+\frac{R^{2}}{2}\right) \frac{\partial \gamma(\theta)}{\partial \theta}\right] \\
& \times\left(\frac{\partial \theta^{*}(R, Z)}{\partial R}+R\right) \frac{d \tilde{\Psi}_{i}(R)}{d R} d R-\mu_{i}^{2} \int_{0}^{1} R \gamma(\theta) \\
& \times\left[\theta^{*}(R, Z)+\frac{R^{2}}{2}\right] \tilde{\Psi}_{i}(R) d R
\end{aligned}
$$

with the transformed inlet conditions

$$
\bar{f}_{i}=-\frac{1}{2} \int_{0}^{1} R^{3} \tilde{\psi}_{i}(R) d R
$$

Also, the linear coefficients matrix in the convection term is readily computed in analytic form, and inverted only once to provide the desired explicit transformed system for numerical solution. In fact, this advantage of one single inversion justifies writing Eq. (4a) with only the linear fully developed velocity component in the convection term, moving the nonlinear component to the right-hand side. The coefficients are obtained from:

$$
a_{i, j}=\int_{0}^{1} R U_{f d}(R) \tilde{\Psi}_{i}(R) \tilde{\psi}_{j}(R) d R
$$

The dimensionless velocity field is given by direct integration of the momentum equation in the form:

$$
U(R, Z)=\frac{1}{2} \frac{\int_{0}^{1} \frac{R^{\prime}}{\Lambda(\theta)} d R^{\prime}}{\int_{0}^{1} R^{\prime} \int_{R^{\prime}}^{1} \frac{R^{\prime \prime}}{\Lambda(\theta)} d R^{\prime \prime} d R^{\prime}}
$$

where the dimensionless viscosity is written as

$$
\Lambda(\theta)=\frac{\mu(T)}{\mu_{0}}
$$

Once the temperature distribution has been obtained with prescribed accuracy, quantities of practical interest such as bulk temperature and local and average Nusselt numbers can be readily obtained from their analytical expressions.

\section{SYNTHESIS AND CHARACTERIZATION OF THE NANOFLUIDS}

The accurate identification of nanofluid thermal properties requires successful procedures for creating stable suspensions of nanoparticles in the base liquids. In this study, a two-step process was used for the preparation of nanofluids, consisting first of the preparation of nanoparticles as a dry powder and then dispersing them into a base fluid in a second processing step.
The high surface area of nanoparticles makes them reactive with respect to the solvent and the ionic/molecular species present in the base fluid, so that phenomena like surface complexations and hydroxylation can occur. All these processes can alter the interface characteristics of the particles and affect the stability of the suspension, so it is of critical importance to analyze the characteristics of the involved nanoparticles such as morphology, particles size distribution, and crystallinity, as well as surface properties like zeta potential [29].

The morphology and the particle size of the starting powders were analyzed by scanning electron microscope (SEM). The crystalline phases were characterized by $\mathrm{x}$-ray diffraction (XRD) measurement performed on the starting powder and on the powder after dispersion tests.

The stability of the suspensions was monitored by electrokinetic sonic amplitude (EAS) measurements (AcoustosizerII). The simultaneous determination of zeta potential and particle size distribution allows to evaluating the stability of nanoparticles suspensions and to identifying the best conditions for the preparation of nanofluids.

In this study, commercial $\alpha-\mathrm{Al}_{2} \mathrm{O}_{3}$ nanoparticles were used, and ultrapure water (Milli-Q) was employed as the base fluid. Nanofluids with different volumetric concentrations of nanoparticles were prepared in order to verify the stability of the dispersions.

The nanoparticles, dried out in a oven at $120^{\circ} \mathrm{C}$ for $24 \mathrm{~h}$, and the base fluid were initially mixed with a magnetic stirrer and then processed with an ultrasonic probe to minimize particle aggregation and improve dispersion behavior.

Figure 1a shows an SEM micrograph of the raw $\alpha-\mathrm{Al}_{2} \mathrm{O}_{3}$ nanoparticles. The morphology of the nanoparticles is regular and their shape is approximately spherical, however large agglomerates are present. The mean particle size of nanoparticles as received, obtained by SEM observation, is about $99 \mathrm{~nm}$.

The XRD spectra of the $\alpha-\mathrm{Al}_{2} \mathrm{O}_{3}$ raw powder is shown in Figure 1b. The peaks of the $\alpha$-phase are well defined, narrow, and present high intensity, indicating its high crystallinity. The XRD analysis carried out with $\alpha-\mathrm{Al}_{2} \mathrm{O}_{3}$ nanoparticles after 1 month of contact with the base fluid has shown the same diffraction spectra, indicating the absence of hydratation or dissolution process and confirming the stability of crystallographic $\alpha$ phase in the nanofluid.

The effect of ultrasonic processing on the stability of the nanofluids was analyzed. ESA measurements were used to determine the zeta potential and particle size distribution of a 1 vol. $\% \alpha-\mathrm{Al}_{2} \mathrm{O}_{3}$ nanofluid as a function of ultrasonication time, and the results are presented in Figure 2. The zeta potential slowly increases with the processing time up to the maximum value of $13.4 \mathrm{mV}$, after $40 \mathrm{~min}$ of ultrasonication. This value, however, is too low for an effective electrostatic stabilization of the suspension, so the use of a dispersant is critical to obtain a more stable suspension. The indices $\mathrm{d} 15, \mathrm{~d} 50$, and $\mathrm{d} 85$ represent the particle size values for which $15 \%, 50 \%$, and $85 \%$ of the nanoparticles, respectively, have a diameter lower than those indicated in the figure. The results show a reduction of the 

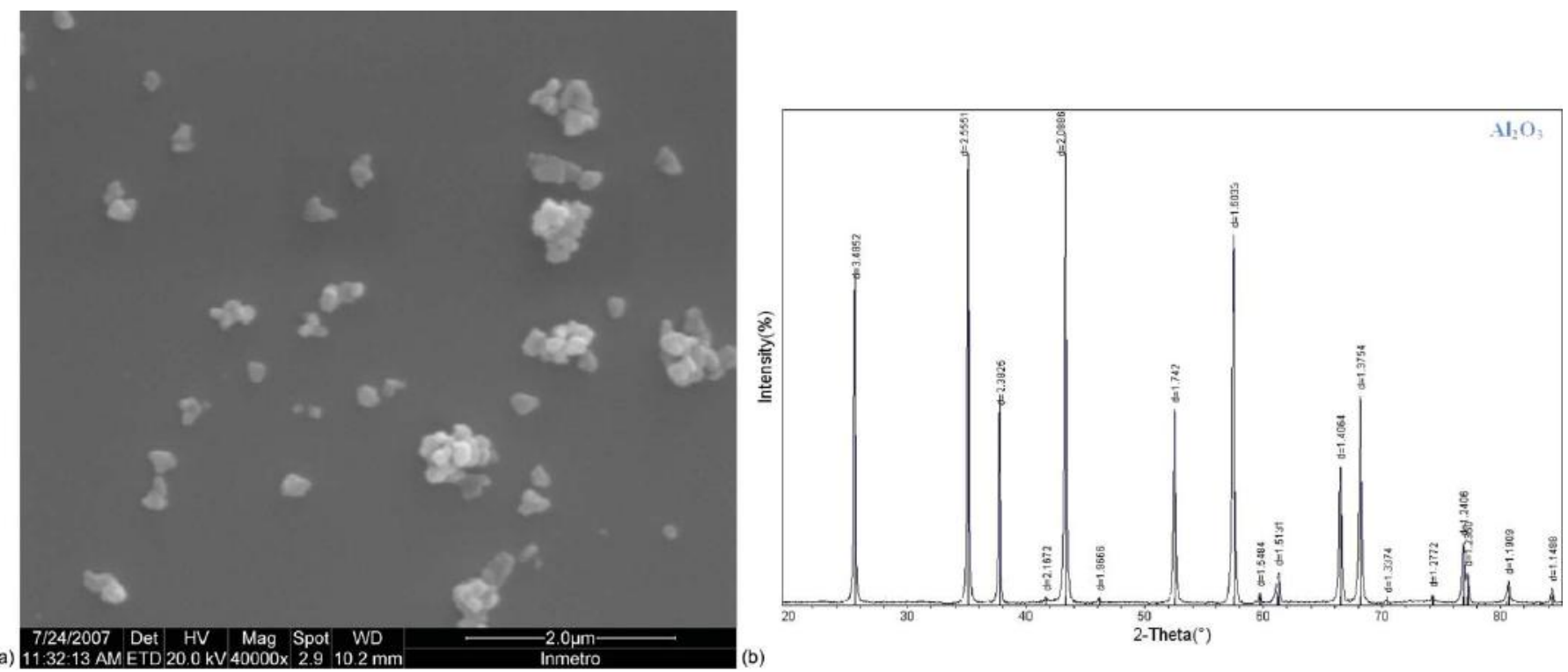

Figure 1 (a) SEM micrography of $\alpha$-alumina $\left(\alpha-\mathrm{Al}_{2} \mathrm{O}_{3}\right)$ raw nanoparticles. (b) Spectra of x-rays diffraction of $\alpha$-alumina $\left(\alpha-\mathrm{Al}_{2} \mathrm{O}_{3}\right)$ raw nanoparticles. $(\mathrm{Color}$ figure available online.)

mean particles size with ultrasonication time, and after 40 min of ultrasound exposition no further size reduction was achieved. The resulting nanofluid shows a $\mathrm{pH}$ near to neutrality and mean particle size of $77 \mathrm{~nm}$, which is adequate for preparation of the nanofluid.

For the forced convection experiments, since a larger volume of suspension was required, ball milling was employed as the dispersion method. Glass spheres with $0.5 \mathrm{~mm}$ diameter were added to the suspension (in the proportion of $40 \mathrm{wt} \%$ ), and then the nanofluids were ball milled for $48 \mathrm{~h}$. After removing the milling media, some samples were collected in order to measure the zeta potential and the particle size distribution. Figure 3 shows the cumulative particle size distributions for the nanofluids with 1.6 vol\% and 2 vol\% of $\alpha$-alumina and $1 \mathrm{wt} \%$ (with respect to the nanoparticles) of the dispersant Tamol. The mean particle sizes in these nanofluids are respectively $47 \mathrm{~nm}$ and $76 \mathrm{~nm}$ and the measured values of zeta potential are $19.6 \mathrm{mV}$

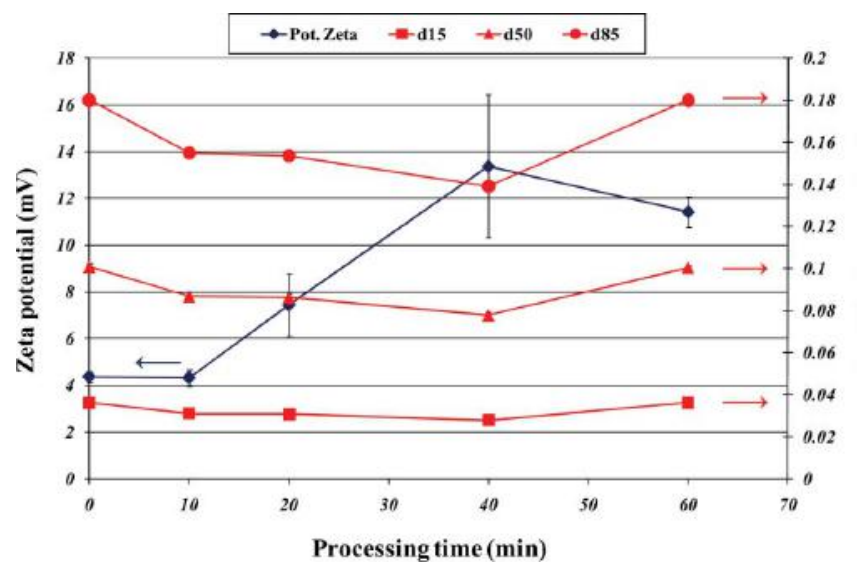

Figure 2 Zeta potential and particles size distribution as a function of the ultrasonication time. (Color figure available online.) and $16.1 \mathrm{mV}$. The zeta potential is higher than the values previously obtained without dispersant, because of the absorption of the polyelectrolyte used as dispersant. Moreover, the electrosteric stabilization, due to the dispersant, allows the nanofuids to be stable during forced convection tests. After the tests only a very low level of sedimentation was observed, indicating a negligible degree of sedimentation, as highlighted by the particle size distributions of nanofluids.

\section{EXPERIMENTAL SETUP AND PROCEDURE}

The thermohydraulic circuit is divided into five parts: heater system, test section, hydraulic circuit, heat rejection system, and data acquisition system. The heater system consists of an electrical resistance in the form of a metallic tape that was installed over the surface of an electrically insulated copper

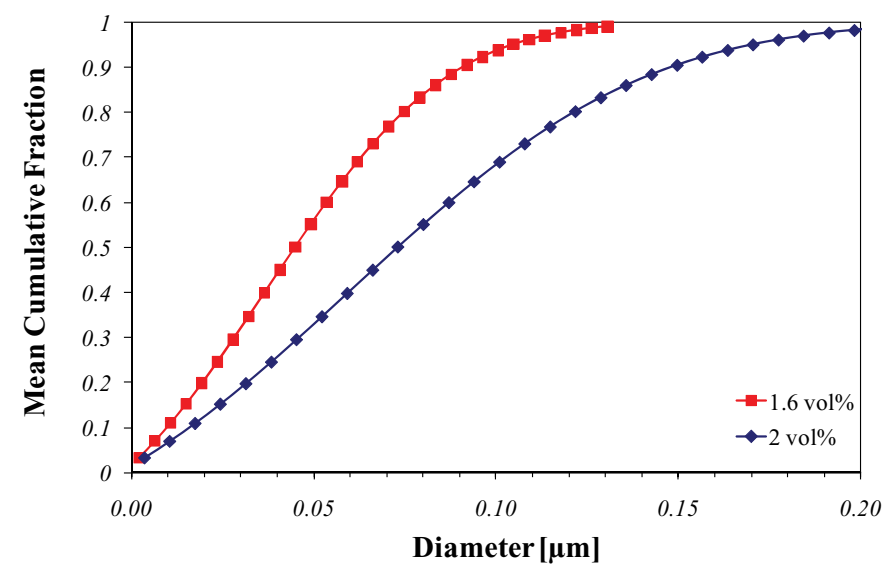

Figure 3 Particle size cumulative distribution for the nanofluids with $1.6 \%$ and $2 \%$ nominal volumetric concentration with dispersant and after dispersion in ball mill. (Color figure available online.)

vol. 34 nos. 5-6 2013 


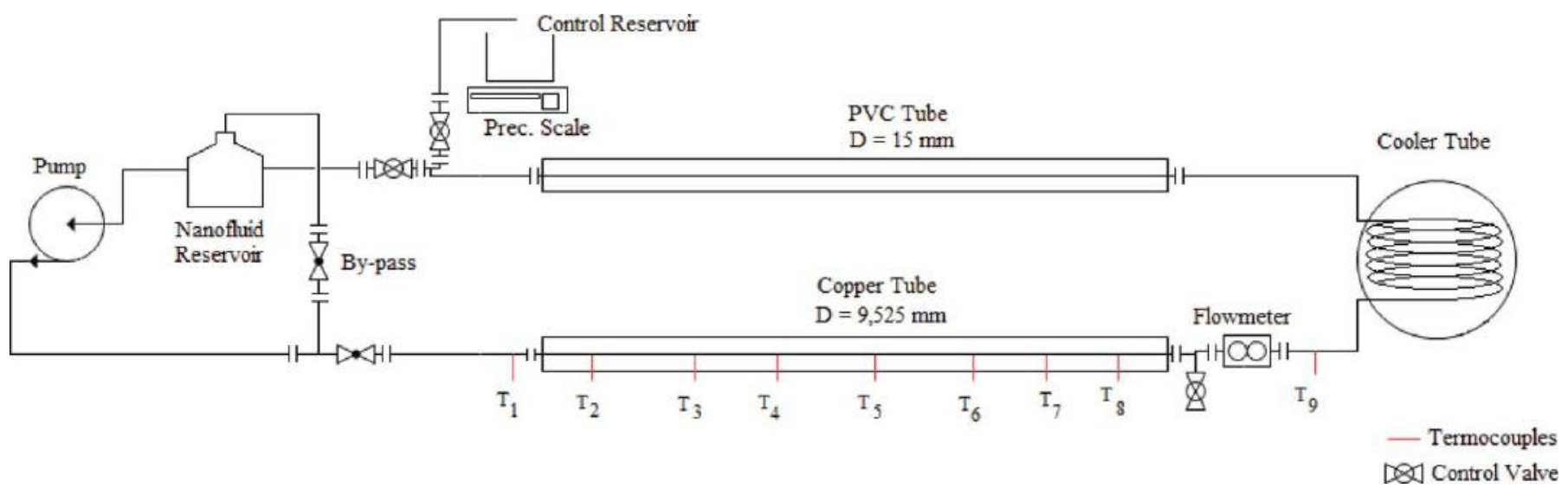

Figure 4 Schematic representation of the experimental apparatus for thermohydraulic analysis of nanofluids. (Color figure available online.)

tube treated with electrostatic painting, to allow for an uniform heat flux along the pipe wall, which is thermally insulated over its length after being covered with Kapton tape.

The heater system also includes a Variac that gives a variableoutput AC voltage from 0 to 300 VAC. Upon leaving the Variac, the alternating current is rectified, filtered, and applied to the resistance tape wound on the copper tube. The DC supply has eliminated small electromagnetic induction noise caused in the reading of the thermocouples. This setup allows applying to the tube a heating power adjustable from 0 to $1500 \mathrm{~W}$. The circuit has a 20-A circuit breaker to protect it and also serves as a key drive. The reading of electrical parameters is performed by a digital ammeter (A), which measures the current within the heater, and a digital voltmeter $(\mathrm{V})$, which measures the supplied voltage, while the resistance of the heater is measured in both ambient and heated states.

The test section consists of a copper tube with outer diameter of $3 / 8$ inch and wall thickness of 1/16 inch. The wall temperature measurements along the tube are provided by type $\mathrm{K}$ (chromel-alumel) thermocouples placed on the external copper wall. To measure the temperature within the fluid, type $\mathrm{E}$ (chromel-constantan) thermocouples were placed inside mixing connections at the inlet and outlet of the test section. For the thermal insulation of the test section, glass wool has been chosen.

The hydraulic circuit is composed of the fluid storage tank, the pump, hoses, valves for flow control, the return pipe, and a solenoid valve for mass flow rate measurements. A peristaltic pump has been chosen to prevent the contamination of the fluid, employing a nontoxic hose and avoiding contact with the mechanical seals and other pump parts. For mass flow rate measurements a precision digital scale has been used for such low flow rates, where readings of mass versus time are automatically acquired through the RS232 output of the precision scale. At least six successive mass flow rate measurements are recorded, at the end of each experimental run, for statistical data analysis.

The heat rejection system consists of a shell-and-coil heat exchanger, made of about 20 coiled sections of $18-\mathrm{cm}$-diameter 3/8-inch copper tube, subjected to a shell-side water stream at room temperature. The acquisition system was based on a data logger connected to a microcomputer, and the experimental apparatus is schematically described in Figure 4.

The implemented experimental procedure was designed for steady-state measurements. In synthesis, one first checks the fluid level in the reservoir to power on the pump, adjusting its rotation. The data acquisition system is connected and the control valve for the heat exchanger cooling water is adjusted. Only then the heater system is turned on. When the system achieves its steady state, the precision scale is powered and tared, and one measures the voltage and current in the resistance, and measures the mass flow rate. At the end of each test the system is cooled back again, after the shutdown of the heating power. In the case of exchange of fluid, the purge valve located before the entry to the shell-and-coil heat exchanger is used, the lowest point of the thermal circuit.

In the results here reported, around $3 \mathrm{~L}$ of the synthesized alumina-water nanofluids have been utilized in the circuit, with different nominal volumetric concentrations of aluminum oxide nanoparticles. Apparently, due to the high concentration of nanoparticles and the not fully effective dispersion method or dispersant employed, some sedimentation of nanoparticles in the thermohydraulic circuit can still be observed after each new test batch was concluded. This observation has alerted us to measure concentrations after each set of runs, which would then be more representative of the actual concentrations during the tests. In fact, the postoperational measured value of $1.2 \%$ in volume concentration is more representative of the actual flowing fluid conditions in the set of experimental runs to be here reported.

To calculate the effective properties of the nanofluid, first the following expressions for the density and specific heat have been used, as obtained from the conventional mixtures theory:

$$
\begin{aligned}
\rho_{n f} & =(1-\phi) \rho_{f b}+\phi \rho_{p} \\
c_{p, n f} & =\left[(1-\phi) \rho_{f b} c_{p, f b}+\phi \rho_{p} c_{p, p}\right] / \rho_{n f}
\end{aligned}
$$

For the thermal conductivity, the Hamilton and Crosser correlation [30] has been adopted, with the empirical form factor 
defined as $n=3$ for nanoparticles with spherical shape, since it has provided the best agreement with experimental results obtained in our previous work, using both the hot wire and flash techniques [20]:

$$
\begin{gathered}
k_{n f}=k_{f b}\left(k_{p}+(n-1) k_{f b}-(n-1) \varphi\left(k_{f b}-k_{p}\right) /\right. \\
\left(k_{p}+(n-1) k_{f b}-\varphi\left(k_{f b}-k_{p}\right)\right)
\end{gathered}
$$

In addition, the temperature dependence of the thermophysical properties was found to closely follow that of the base fluid (pure water) in the range of temperatures achieved in these experiments [20]. The viscosity was measured at different shear rates and temperatures, and exhibited a Newtonian behavior [20]. The confirmation of the expected behavior for the thermophysical properties is in accordance with a recent benchmark study involving different research groups but the same nanofluid samples [31].

The literature provides a few different correlations, either theoretical or empirical, to predict the Nusselt number for laminar flow as a function of dimensionless axial distance, in the form of Graetz number (Gz) [26]. However, some of the reviewed work on forced convection with nanofluids reported heat transfer rates augmentation that does not seem to be explainable only by changing the effective thermophysical properties in comparison with the base fluid, and thus might not be predictable by the classical correlations for heat transfer coefficients in laminar flow. Therefore, two correlations for laminar forced convection that are well accepted in the literature have been recalled, the first one a theoretical correlation based on the analytical solution of the so-called Graetz problem for prescribed heat flux [32], and the correlation of experimental data performed in reference [33], which also provides a correction on the heat transfer coefficient for the variation of viscosity with temperature. The two expressions, respectively, for local and average Nusselt numbers, are given by:

Churchill and Ozoe [33]:

$$
\begin{aligned}
& \frac{N u_{l}+1.7}{5.357\left[1+(G z / 97)^{8 / 9}\right]^{3 / 8}} \\
& =\left[1+\left(\frac{G z / 71}{\left[1+(\operatorname{Pr} / 0.0468)^{2 / 3}\right]^{1 / 2}\left[1+(G z / 97)^{8 / 9}\right]^{3 / 4}}\right)^{4 / 3}\right]^{3 / 8}
\end{aligned}
$$

Shah [32]:

$$
N u_{m}= \begin{cases}\frac{1.953}{(\chi)^{1 / 3}}, & \chi \leq 0.03 \\ 4.354+\frac{0.0722}{\chi}, & \chi>0.03\end{cases}
$$

heat transfer engineering where

$$
\chi=\frac{1}{G z}=\frac{z / D}{\operatorname{RePr}}
$$

Equation (14a) may also be numerically integrated to provide the average Nusselt number as a function of the dimensionless axial position (inverse of the Graetz number).

\section{RESULTS AND DISCUSSION}

The proposed model and solution methodology were implemented in the mixed symbolic-numerical platform Mathematica [21], and first a few representative results were obtained to illustrate the convergence behavior of the eigenfunction expansions. A test case has been selected, and employed in the model and code validations, for pure water laminar flow with the following pertinent data: $r_{w}=0.00315 \mathrm{~m} ; q_{w}=7188.4 \mathrm{~W} / \mathrm{m}^{2} ; L=2.45 \mathrm{~m}$; $\mathrm{u}_{0}=0.197 \mathrm{~m} / \mathrm{s} ; T_{0}=21.4^{\circ} \mathrm{C} ; k_{0}=0.6 \mathrm{~W} /\left(\mathrm{m}-{ }^{\circ} \mathrm{C}\right) ; \alpha_{0}=1.434 \times$ $10^{-7} \mathrm{~m}^{2} / \mathrm{s} ; \nu_{0}=9.790 \times 10^{-7} \mathrm{~m}^{2} / \mathrm{s}$.

The resulting Reynolds number is around $\mathrm{Re}=1632$ and the Prandtl number is $\operatorname{Pr}=5.1$. All the thermophysical properties were allowed to vary with temperature, including viscosity and its corresponding effect on the velocity field. A few selected positions at the external wall along the tube were taken corresponding to thermocouple locations in the experimental setup, and are here used to illustrate the convergence behavior of the eigenfunction expansion implemented. Thus, Table 1 shows the convergence behavior of the duct wall temperature at the chosen axial positions. The maximum system truncation order is taken as $\mathrm{N}=8$, and $\mathrm{NI}=36$ segments are employed in the semi-analytical integration of the system coefficients vectors. Clearly, the integral transform results with truncation orders up to $\mathrm{N}=8$ already offer a convergence to the third significant digit in the wall temperature along the duct length.

Figure 5 illustrates the dimensionless temperature radial distributions along the channel length, for the same axial locations

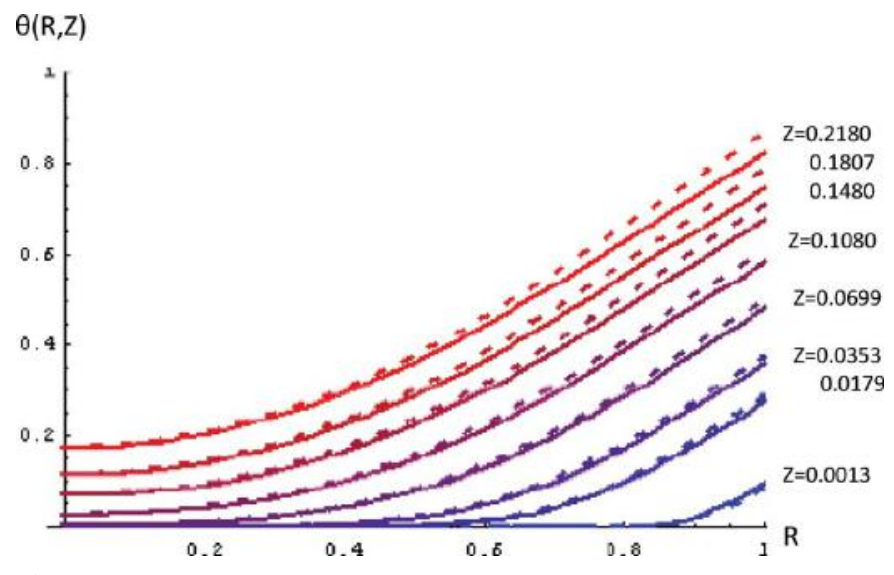

Figure 5 Dimensionless radial temperature distributions for linear (dashed lines) and nonlinear (solid lines) formulations and dimensionless axial positions increasing from lower to upper pairs of curves $(Z=0.0013,0.0179,0.0353$, $0.0699,0.1080,0.1480,0.1807,0.2180$ ). (Color figure available online.) 
Table 1 Convergence of dimensional duct wall temperature at different axial positions, $z[\mathrm{~m}](\mathrm{N} \leq 8, \mathrm{NI}=36$ segments $)$

\begin{tabular}{lccccccc}
\hline & $\mathrm{z}=0.014 \mathrm{~m}$ & $\mathrm{z}=0.197 \mathrm{~m}$ & $\mathrm{z}=0.388 \mathrm{~m}$ & $\mathrm{z}=0.767 \mathrm{~m}$ & $\mathrm{z}=1.185 \mathrm{~m}$ & $\mathrm{z}=1.625 \mathrm{~m}$ & $\mathrm{z}=1.983 \mathrm{~m}$ \\
\hline $\mathrm{N}=2$ & 26.410 & 30.575 & 33.305 & 37.419 & 41.017 & 44.246 & 46.616 \\
$\mathrm{~N}=3$ & 25.185 & 30.634 & 33.719 & 37.949 & 41.461 & 44.580 & 46.877 \\
$\mathrm{~N}=4$ & 24.737 & 30.878 & 33.941 & 38.053 & 41.502 & 44.594 & 46.879 \\
$\mathrm{~N}=5$ & 24.559 & 31.000 & 33.992 & 38.060 & 41.498 & 44.583 & 46.865 \\
$\mathrm{~N}=6$ & 24.490 & 31.038 & 33.999 & 38.056 & 41.489 & 44.571 & 49.344 \\
$\mathrm{~N}=7$ & 24.459 & 31.046 & 33.998 & 38.051 & 41.481 & 44.560 & 46.850 \\
$\mathrm{~N}=8$ & 24.429 & 31.047 & 33.996 & 38.046 & 41.474 & 44.551 & 46.319 \\
\hline
\end{tabular}

as considered in Table 1, which are here represented from bottom to top $(\mathrm{Z}=0.0013,0.0179,0.0353,0.0699,0.1080,0.1480$, $0.1807,0.2180)$. The solid lines correspond to the full nonlinear formulation here considered, while the dashed lines are obtained from the classical linear formulation of the Graetz problem (constant properties) with the second kind of boundary condition. As expected, the deviations are more significant within the regions of larger temperature gradients, corresponding to regions closer to the wall and as the fluid heating progresses along the channel. Also, the heat transfer enhancement effect may be observed in the reduction of the duct wall temperatures as the nonlinear properties are accounted for, especially due to

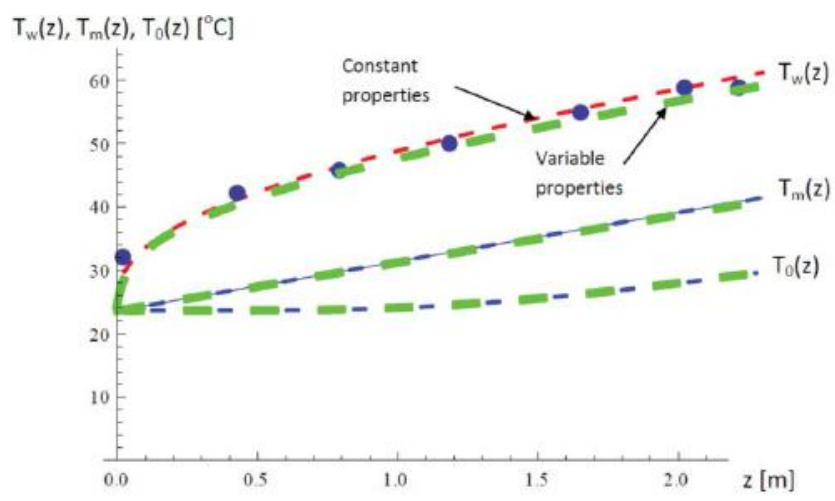

(a)

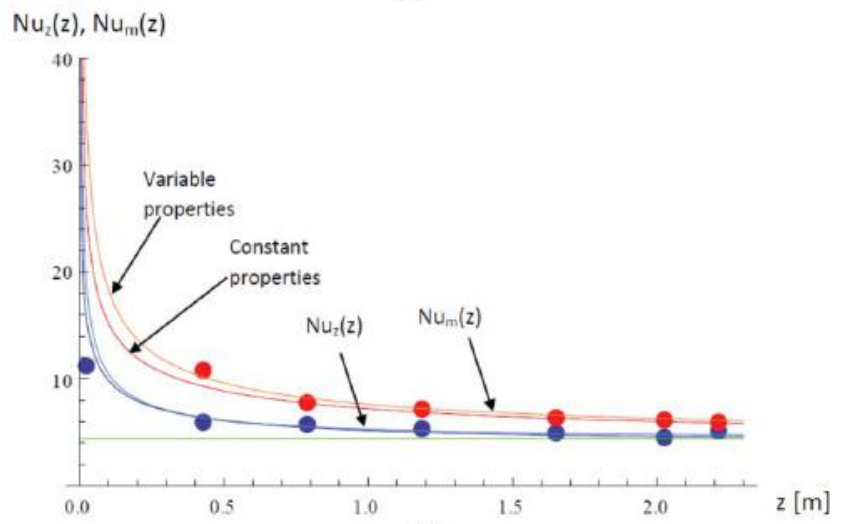

(b)

Figure 6 Experimental (dots), linear (short dashes), and nonlinear (long dashes) theoretical results for (a) wall, bulk, and centerline temperatures and (b) local (lower curves and dots) and average Nusselt numbers, for pure water in laminar flow with $\mathrm{Re}=1531$. (Color figure available online.) the reduction of the viscosities close to the hotter duct wall, with the subsequent fluid acceleration in this region.

Experimental results of pure water were also obtained for model verification purposes, and are illustrated in Figure 6 for a Reynolds number equal to 1531. In Figure 6a the temperatures measured along the tube wall (dots) are compared with the solution of the constant properties linear model (short dashed lines) and the temperature-dependent properties (nonlinear) model (long dashed). In Figure 6b, the local (lower dots) and average (upper dots) Nusselt numbers determined from the measured temperatures are compared with theoretical predictions for the local Nusselt (lower line) and average Nusselt (upper line) numbers. The dots in each case are the experimental results and show good agreement with theoretical predictions, with a slightly better adherence to the temperature dependent properties model results. Also, Figure 7 illustrates the repeatability of the experimental procedure, showing the average heat transfer coefficients obtained for two distinct experimental runs, for $\operatorname{Re}=2008$ and 2018 with water, where the agreement is practically perfect to the graph scale. Temperature uncertainties, after metrological thermocouples calibration, were held to within $0.3^{\circ} \mathrm{C}$, and, combined with the remaining parameters estimated errors, lead to an uncertainty of about $8 \%$ in the local Nusselt numbers.

Both experiments and simulations for the nanofluids were undertaken for a wide range of Reynolds numbers within the

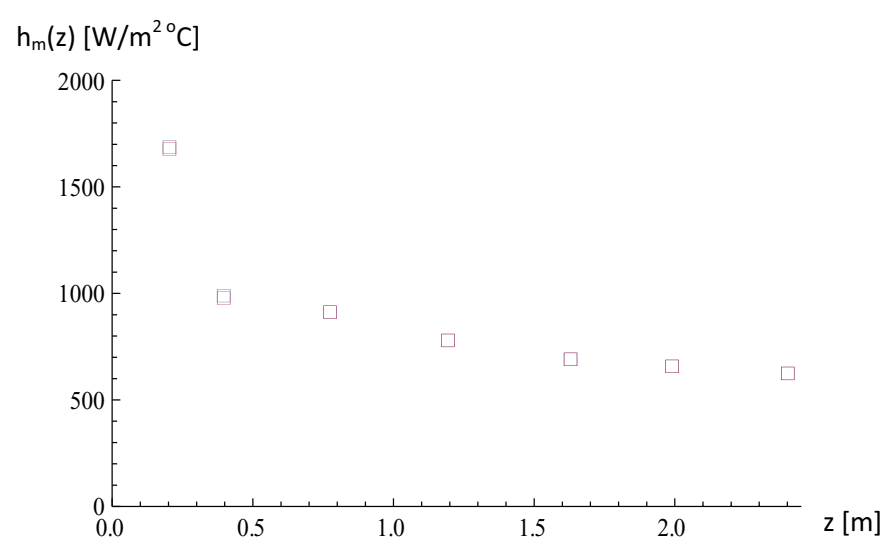

Figure 7 Repeatability of the experimental procedure: average heat transfer coefficients for two distinct experimental runs with water and $\mathrm{Re}=2008$ and 2018. (Color figure available online.) 
Table 2a Comparison of experimental average heat transfer coefficients for water-alumina nanofluid and pure water: nanofluid $(\operatorname{Re}=1616)$ with postoperational concentration of $1.2 \%$ and water $(\operatorname{Re}=1604$ and $\operatorname{Re}=1632)$

\begin{tabular}{|c|c|c|c|c|c|c|}
\hline$z[\mathrm{~m}]$ & $\begin{array}{c}h_{m}\left[\mathrm{~W} / \mathrm{m}^{2}-{ }^{\circ} \mathrm{C}\right] \text { nanofluid } \\
\operatorname{Re}=1616\end{array}$ & $\begin{array}{c}h_{m}\left[\mathrm{~W} / \mathrm{m}^{2}-{ }^{\circ} \mathrm{C}\right] \\
\text { water, } \mathrm{Re}=1604\end{array}$ & $\begin{array}{c}\text { Deviation } \\
(\%)\end{array}$ & $\begin{array}{c}h_{m}\left[\mathrm{~W} / \mathrm{m}^{2}-{ }^{\circ} \mathrm{C}\right] \\
\text { water, } \mathrm{Re}=1632\end{array}$ & $\begin{array}{c}\text { Deviation } \\
(\%)\end{array}$ & $\begin{array}{c}\text { Interpolation } \\
\text { deviation (\%) }\end{array}$ \\
\hline 0.767 & 932.6 & 831.3 & 12.2 & 850.5 & 9.64 & 11.1 \\
\hline 1.625 & 689.2 & 649.0 & 6.18 & 662.1 & 4.09 & 5.28 \\
\hline 1.983 & 648.3 & 615.3 & 5.36 & 629.5 & 2.99 & 4.34 \\
\hline 2.393 & 615.0 & 583.7 & 5.38 & 597.5 & 2.94 & 4.33 \\
\hline
\end{tabular}

laminar flow region, and in order to illustrate such analysis sample results for different values of Reynolds number and a nanofluid with postoperational concentration of $1.2 \%$ were selected. Table $2 \mathrm{a}$ provides a direct comparison of the experimental average heat transfer coefficients for the nanofluid with postoperational concentration of $1.2 \%$ and $\operatorname{Re}=1616$, with two experiments with pure water for bounding Reynolds number values $(\operatorname{Re}=1604$ and $\operatorname{Re}=1632)$, in light of the difficulty in matching the Reynolds numbers with different experiments for different fluids. Therefore, one may estimate from these two values the deviations between the nanofluid and the pure water experimental results, yielding the last column in Table $2 \mathrm{a}$, which ranges from $11 \%$ enhancement closer to the channel entrance $(z=0.767 \mathrm{~m})$ down to around $4.3 \%$ in the fully developed region. Similarly, Table $2 b$ considers a lower value of the Reynolds number for the nanofluid, $\mathrm{Re}=1335$, comparing the average heat transfer coefficient along the tube with two other experiments with water, for a lower and an upper value of Reynolds, respectively, $\operatorname{Re}=1227$ and 1413. Again, the interpolated deviations result in an enhancement that goes from around $11 \%$ for the point closer to the inlet $(\mathrm{z}=0.767 \mathrm{~m})$ to about $7.3 \%$ at the end of the tube, in the fully developed region. The heat transfer enhancement effect may also be graphically observed in Figures 8a and $b$ for a couple of different values of Reynolds number, which shows the experimental average heat transfer coefficient estimated at each thermocouple axial position, for the nanofluid with $1.2 \%$ volumetric concentration, and for two other values of Reynolds number for water, one above and one below the corresponding Reynolds for the nanofluid. In both sets of data, the nanofluid results are represented by the dots most on top of the graphs, even though they represent an intermediate Reynolds number, respectively, $\mathrm{Re}=1515$ and 1189 in Figures 8a and b, while the Reynolds numbers

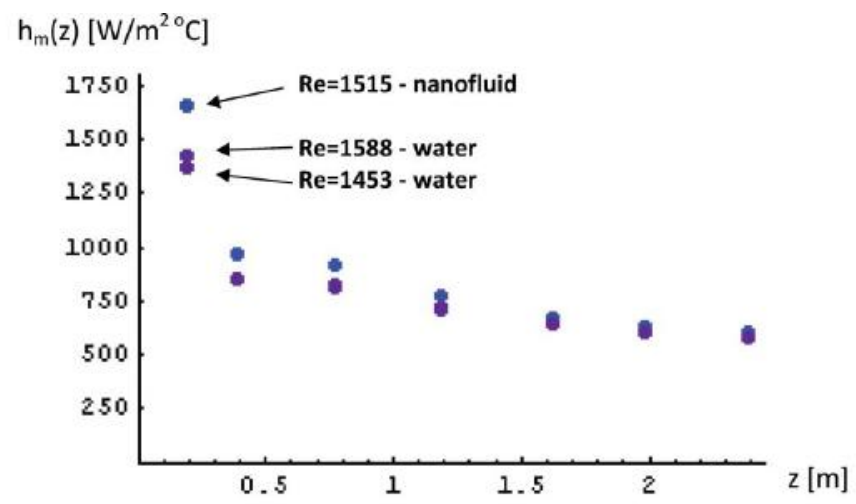

(a) $\operatorname{Re}=1515$ for nanofluid, $\operatorname{Re}=1453$ and 1588 for water.

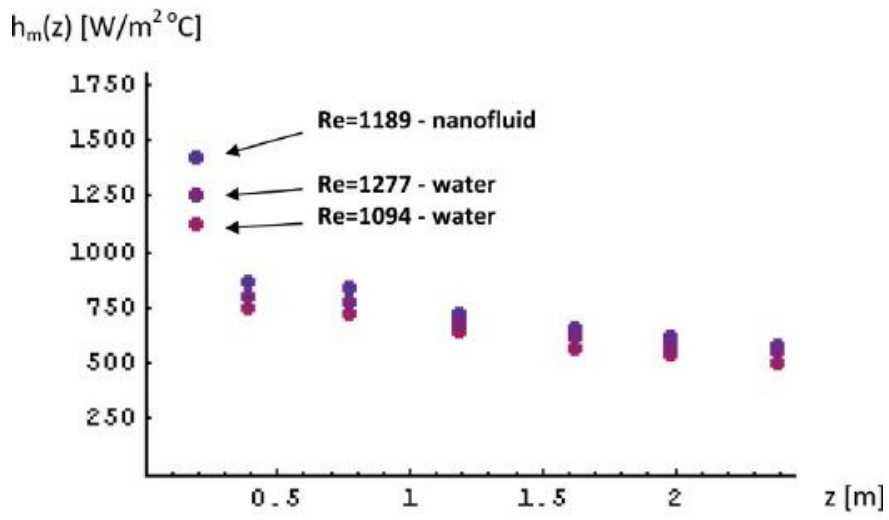

(b) $\operatorname{Re}=1189$ for nanofluid, $\operatorname{Re}=1094$ and 1277 for water.

Figure 8 Comparison of average heat transfer coefficients at different positions along the channel for the nanofluid with $1.2 \%$ volumetric concentration (upper dots) and two other experiments with pure water for a lower and a higher value of Reynolds number. (Color figure available online.)

Table 2b Comparison of experimental average heat transfer coefficients for water-alumina nanofluid and pure water: nanofluid $(\operatorname{Re}=1335)$ with postoperational concentration of $1.2 \%$ and water $(\operatorname{Re}=1277$ and $\operatorname{Re}=1413)$

\begin{tabular}{|c|c|c|c|c|c|c|}
\hline$z[\mathrm{~m}]$ & $\begin{array}{c}h_{m}\left[\mathrm{~W} / \mathrm{m}^{2}-{ }^{\circ} \mathrm{C}\right] \text { nanofluid } \\
\mathrm{Re}=1335\end{array}$ & $\begin{array}{c}h_{m}\left[\mathrm{~W} / \mathrm{m}^{2}-^{\circ} \mathrm{C}\right] \\
\text { water, } \mathrm{Re}=1227\end{array}$ & $\begin{array}{l}\text { Deviation } \\
(\%)\end{array}$ & $\begin{array}{c}h_{m}\left[\mathrm{~W} / \mathrm{m}^{2}-^{\circ} \mathrm{C}\right] \\
\text { water, } \mathrm{Re}=1413\end{array}$ & $\begin{array}{l}\text { Deviation } \\
\quad(\%)\end{array}$ & $\begin{array}{l}\text { Interpolation } \\
\text { deviation (\%) }\end{array}$ \\
\hline 0.767 & 864.2 & 768.8 & 12.4 & 789.8 & 9.42 & 11.1 \\
\hline 1.625 & 660.6 & 609.0 & 8.48 & 620.2 & 6.52 & 7.64 \\
\hline 1.983 & 623.8 & 577.1 & 8.09 & 586.8 & 6.32 & 7.33 \\
\hline 2.393 & 589.5 & 544.7 & 8.22 & 555.0 & 6.22 & 7.37 \\
\hline
\end{tabular}



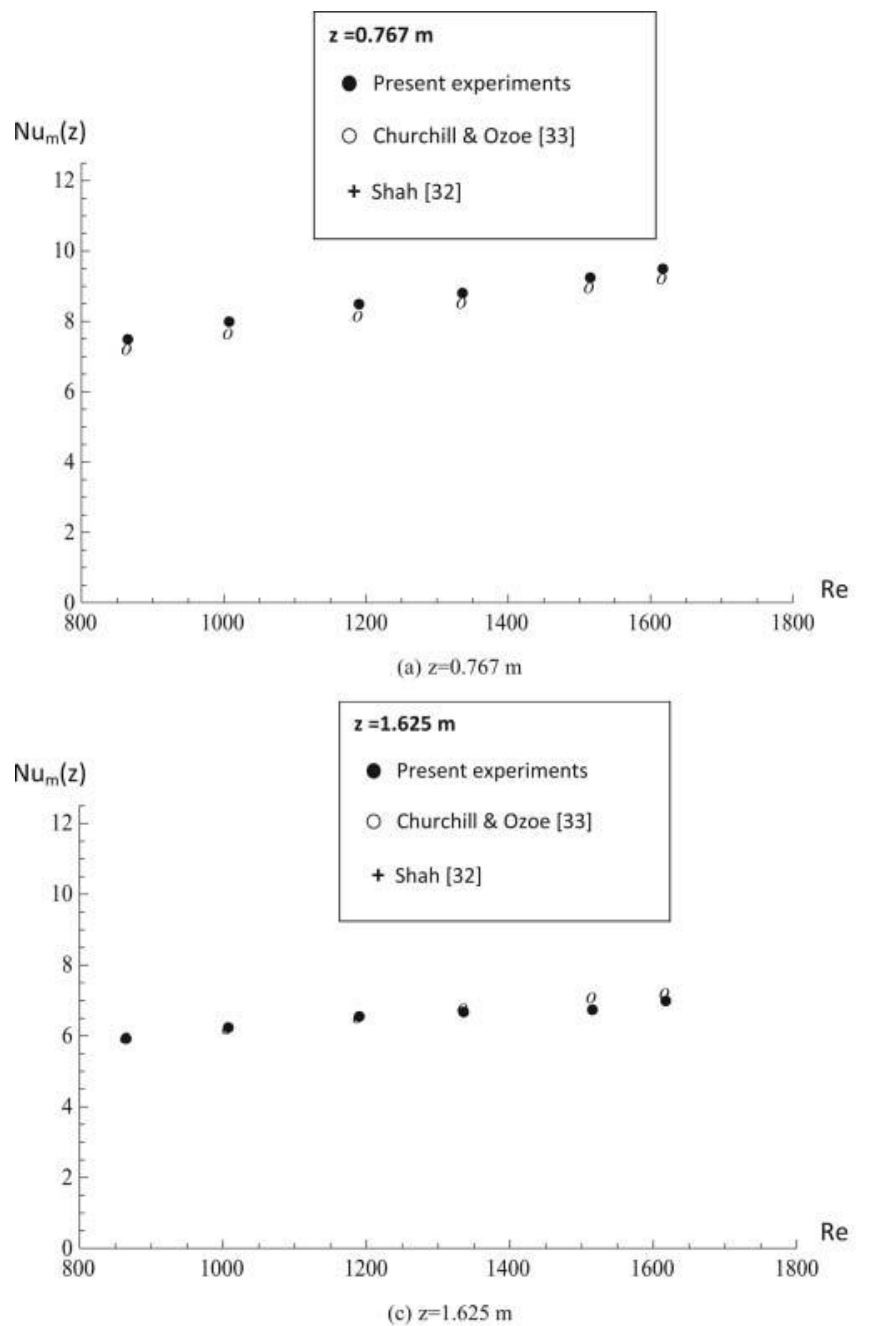

$\mathrm{Nu}_{\mathrm{m}}(\mathrm{z})$

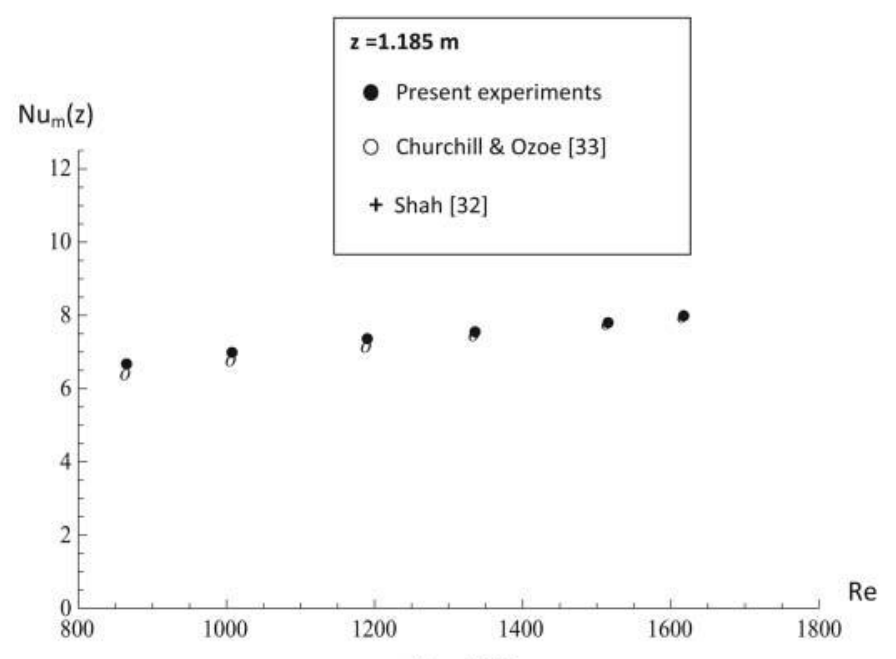

(b) $\mathrm{z}=1.185 \mathrm{~m}$

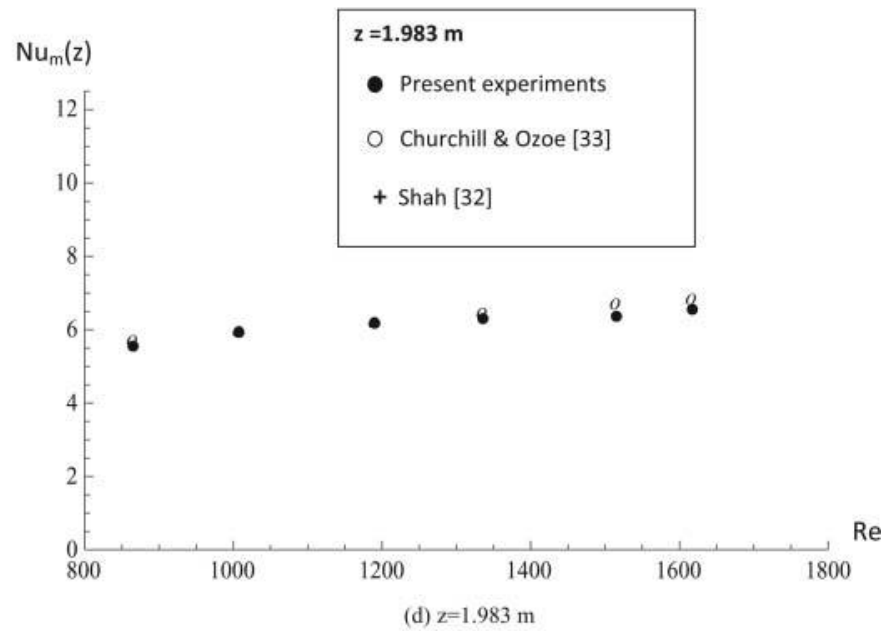

$\mathrm{z}=2.393 \mathrm{~m}$

- Present experiments

O Churchill \& Ozoe [33]

+ Shah [32]

$\mathrm{Re}$

(e) $z=2.393 \mathrm{~m}$

Figure 9 Experimental results for the average Nusselt number for the nanofluid with postoperational concentration of 1.2\%, in black dots, compared with the results from the correlations of Shah [32], plus signs, and Churchill and Ozoe [33], in circles: (a) $\mathrm{z}=0.767 \mathrm{~m}$, (b) $\mathrm{z}=1.185 \mathrm{~m}$, (c) $\mathrm{z}=1.625 \mathrm{~m}$, (d) $\mathrm{z}=1.983 \mathrm{~m}$, and (e) $\mathrm{z}=2.393 \mathrm{~m}$.

for water, in each case, were $\operatorname{Re}=1453$ and 1588, in Figure 8a, and $\mathrm{Re}=1094$ and 1277, for Figure 8b. It is also clear from these graphs that the rate of heat transfer enhancement is somehow larger closer to the inlet than at the fully developed region.
It is also of interest to compare the experimental results here provided with the most common correlations for internal forced convection, employing the related thermophysical properties at the overall mean temperature in the channel. Thus, the correlations of Shah [32] and of Churchill and Ozoe [33] were taken to 
compute the average Nusselt numbers for various flow conditions with the same nanofluid, for the five axial locations shown above in Table 2. Therefore, Figures 9a-e summarize such comparisons, showing the present experimental results in filled circles, the theoretical results of reference [32] in plus signs, and the reference [33] correlation results in blank circles. Clearly, the overall agreement with the correlations predictions is quite reasonable, with a more noticeable deviation from Shah's [32] theoretical correlation for shorter tube lengths, but with a good agreement with Churchill and Ozoe's [33] even in this range. Therefore, at least in this range of nanoparticles concentrations for this class of nanofluids, the classical correlations allow for a prediction of the convective heat transfer behavior, as long as the thermophysical properties are adequately accounted for, in the form of effective properties, estimated at the global mean temperature.

\section{CONCLUSIONS}

Convective heat transfer of water/ $\alpha$-alumina nanofluids in tubes was studied, both theoretically and experimentally, accounting for temperature dependence of all the thermophysical properties in the theoretical model. The employed nanofluids were synthesized by the two-step method, and two techniques were utilized to disaggregate and disperse the nanoparticles, ultrasound and ball milling. To improve the stability of the suspensions it was necessary to use a dispersant. The nanoparticles and the resulting nanofluids were fully characterized in terms of morphology, crystallinity, zeta potential, and particle size distribution. Experiments and simulations were covalidated for pure water convection, and based on measurements of the relevant thermophysical properties of the nanofluids, experimental findings for convective heat transfer were critically compared with the proposed temperature-dependent properties model results.

It has been observed that the temperature dependence of the thermal conductivity and viscosity plays some role in the prediction of the nanofluids' convective thermal behavior, but most important, one needs to account for operational variations of the nanoparticle concentration, and postoperational measurements of the properties should also be accomplished for a more reliable comparison. It has also been observed that a classical correlation of experimental results in laminar forced convection [33] can predict fairly well the behavior of the tested nanofluids, once effective thermophysical properties are employed according to available expressions in the literature. Therefore, at least in this range of concentrations and Reynolds numbers, it has been found unnecessary to develop specific correlations for the water-alumina nanofluid that employ the concentration as an adjustment factor. In addition, both the constant and variable properties models of laminar forced convection with prescribed wall heat flux were able to reliably reproduce the wall temperature distributions and Nusselt numbers experimentally obtained. At least in the present range of wall and fluid temperatures, the variation of thermophysical properties with temperature provides only a slight deviation in the theoretical results for the heat transfer coefficients, though yielding a better agreement with the experimental results.

\section{NOMENCLATURE}

$a_{i, j}$ implicit system coefficients

$c_{p}$ specific heat $\left[\mathrm{J} / \mathrm{kg}-{ }^{\circ} \mathrm{C}\right]$

$D$ tube diameter

$f_{i} \quad$ transformed inlet condition

Gz Graetz number, dimensionless

$h$ heat transfer coefficient $\left[\mathrm{W} / \mathrm{m}^{2}-{ }^{\circ} \mathrm{C}\right]$

$k$ thermal conductivity $\left[\mathrm{W} / \mathrm{m}-{ }^{\circ} \mathrm{C}\right]$

$n$ empirical form factor in thermal conductivity relation

$N_{i}$ norm or normalization integral

$\mathrm{Nu}$ Nusselt number, dimensionless

$p$ pressure $\left[\mathrm{N} / \mathrm{m}^{2}\right]$

Pr Prandtl number, dimensionless

$P_{f}$ filtered source term

$q_{w}$ prescribed heat flux $\left[\mathrm{W} / \mathrm{m}^{2}\right]$

$r$ radial coordinate [m]

$r_{w}$ internal tube radius [m]

$R$ dimensionless radial coordinate

Re Reynolds number, dimensionless

$T$ temperature $\left[{ }^{\circ} \mathrm{C}\right]$

$T_{0}$ channel inlet temperature $\left[{ }^{\circ} \mathrm{C}\right]$

$u$ fluid velocity components [m/s]

$u_{0}$ average velocity [m/s]

$U$ dimensionless velocity

$v$ fluid velocity components [m/s]

$z$ axial coordinate [m]

$Z$ dimensionless axial coordinate

\section{Greek Symbols}

$\alpha$ thermal diffusivity $\left[\mathrm{m}^{2} / \mathrm{s}\right]$

$\beta_{i}$ eigenvalues

$\Lambda$ dimensionless viscosity

$\phi$ nanoparticles volumetric concentration

$\mu$ absolute viscosity $[\mathrm{kg} / \mathrm{m}-\mathrm{s}]$

$\psi$ eigenfunctions

$v$ kinematic viscosity $\left[\mathrm{m}^{2} / \mathrm{s}\right]$

$\rho$ density $\left[\mathrm{kg} / \mathrm{m}^{3}\right]$

$\theta$ dimensionless temperature

$\chi$ dimensionless axial coordinate, Eq. (14c)

\section{Subscripts}

exp experimental

fd fully developed

fb base fluid

$\mathrm{i}, \mathrm{j}$ order of eigenvalues

1 local

$\mathrm{m}$ average

nf related to nanofluid

o related to inlet condition

$\mathrm{p}$ particle

w wall

X local 


\section{Superscript}

* filtered quantity

\section{REFERENCES}

[1] Choi, S. U. S., Nanofluid Technology: Current Status and Future Research, Korea-U.S. Technical Conference on Strategic Technologies, Vienna, VA, 1998.

[2] Choi, S. U. S., and Eastman, J. A., U.S. Patent No. 6,221,275 B1, Enhanced Heat Transfer Using Nanofluids, April 24, 2001.

[3] Eastman, J. A., Phillpot, S. R., Choi, S. U. S., and Keblinski, P., Thermal Transport in Nanofluids, Annual Review of Materials Research, vol. 34, pp. 219-246, 2004.

[4] Keblinski, P., Eastman, J. A., and Cahill, D. G., Nanofluids for Thermal Transport, Materials Today, June, pp. 36-44, 2005.

[5] Das, S. K., Choi, S. U. S., Patel, H., Heat Transfer in Nanofluids-A Review, Heat Transfer Engineering, vol. 27, no. 10, pp. 3-19, 2006.

[6] Daungthongsuk, W., and Wongwises, S., A Critical Review of Convective Heat Transfer of Nanofluids, Renewable and Sustainable Energy Reviews, vol. 11, pp. 797-817, 2007.

[7] Wang, X., and Mujumdar, A. S., A Review on Nanofluids-Part II: Experiments and Applications, Brazilian Journal of Chemical Engineering, vol. 25, no. 4, pp. 631-648, 2008.

[8] Das, S. K., Choi, S. U. S., Yu, W., and Pradeep, T., Nanofluids: Science and Technology, Wiley, New York, NY, 2008.

[9] Kakaç, S., and Pramuanjaroenkij, A., Review of Convective Heat Transfer Enhancement with Nanofluids, International Journal of Heat and Mass Transfer, vol. 52, pp. 3187-3196, 2009.

[10] Xuan, Y., and Li, Q., Investigation on Convective Heat Transfer and Flow Features of Nanofluids, ASME Journal of Heat Transfer, vol. 125, pp. 151-155, 2003.

[11] Wen, D. S., and Ding, Y. L., Experimental Investigation into Convective Heat Transfer of Nanofluids at the Entrance Region Under Laminar Flow Conditions, International Journal of Heat and Mass Transfer, vol. 47, no. 24, pp. 5181-5188, 2004.

[12] Heris, S. Z., Esfahany, M. N., and Etemad, G., Investigation of $\mathrm{CuO} /$ Water Nanofluid Laminar Convective Heat Transfer through a Circular Tube, Journal of Enhanced Heat Transfer, vol. 13, no. 4, pp. 279-289, 2006.

[13] Mansour, R. B., Galanis, N., and Nguyen, C. T., Effect of Uncertainties in Physical Properties on Forced Convection Heat Transfer with Nanofluids, Applied Thermal Engineering, vol. 27, pp. 240-249, 2007.

[14] Raisee, M., and Moghaddami, M., Numerical Investigation of Laminar Forced Convection of Nanofluids through Circular Pipes, Journal of Enhanced Heat Transfer, vol. 15, no. 4, pp. 335-350, 2008.

[15] Namburu, P. K., Das, D. K., Tanguturi, K. M., and Vajjha, R. S., Numerical Study of Turbulent Flow and Heat
Transfer Characteristics of Nanofluids Considering Variable Properties, International Journal of Thermal Sciences, vol. 48, no. 2, pp. 290-302, 2009.

[16] Rea, U., McKrell, T., Hu, L. W., and Buongiorno, J., Laminar Convective Heat Transfer and Viscous Pressure Loss of Alumina-Water and Zirconia-Water Nanofluids, International Journal of Heat and Mass Transfer, vol. 52, nos. 7-8, pp. 2042-2048, 2009.

[17] Ferrouillat, S., Bontemp, S. A., Ribeiro, J. P., Gruss, J. A., and Soriano, O., Hydraulic and Heat Transfer Study of $\mathrm{SiO}_{2} /$ Water Nanofluids in Horizontal Tubes With Imposed Wall Temperature Boundary Conditions, International Journal of Heat and Fluid Flow, vol. 32, pp. 424-439, 2011.

[18] Escher, W., Brunschwiler, T., Shalkevich, N., Shalkevich, A., Burgi, T., Michel, B., and Poulikakos, D., On the Cooling of Electronics With Nanofluids, ASME Journal of Heat Transfer, vol. 133, pp. 051401-1-11, 2011.

[19] Cotta, R. M., Orlande, H. R. B., Couto, P., Balbo, A., Mota, C. A. A., Massard, H., Naveira, C. P., Pereira, A. G. F., and de Sousa G. P., Nanofluids: Fabrication, Caracterization, Thermophysical Properties, and Forced Convection, Final Project Report, COPPETEC no. PEM7393, under contract for Petrobras Research Center, Rio de Janeiro, Brasil, July 2007.

[20] Fonseca, H. M., Orlande, H. R. B., Tavman, I., and Cotta, R. M., Measurements of Nanofluids Physical Properties, High Temperatures-High Pressures, International Journal of Thermophysical Properties Research, vol. 38, no. 2, pp. 187-197, 2009.

[21] Wolfram, S., The Mathematica Book, 5th Ed., version 7.0, Wolfram Media, Inc., USA, 2008.

[22] Cotta, R. M., Integral Transforms in Computational Heat and Fluid Flow, CRC Press, Boca Raton, FL, 1993.

[23] Cotta, R. M., The Integral Transform Method in Thermal and Fluids Sciences and Engineering, Begell House, New York, NY, 1998.

[24] Cotta, R. M., and Mikhailov, M. D., Hybrid Methods and Symbolic Computations, in Handbook of Numerical Heat Transfer, 2nd ed., eds. W. J. Minkowycz, E. M. Sparrow, and J. Y. Murthy, Wiley, New York, NY, pp. 493-522, 2006.

[25] Cotta, R. M., Santos, C.A.C., and Kakaç, S., Unified Hybrid Theoretical Analysis of Nonlinear Convective Heat Transfer, Proceedings of IMECE2007, ASME paper no. IMECE2007-41412, November 11-15, 2007.

[26] Kakac, S., The Effect of Temperature-Dependent Fluid Properties on Convective Heat Transfer, in Handbook of Single-Phase Convective Heat Transfer, eds. S. Kakac, R. K. Shah, and W. Aung, Wiley, New York, NY, Chapter 18, 1987.

[27] Yang, K. T., Laminar Forced Convection of Liquids in Tubes with Variable Viscosity, ASME Journal of Heat Transfer, vol. 84, pp. 353-362, 1962.

vol. 34 nos. 5-6 2013 
[28] Oliveira Filho, F. S., Guedes, R. O. C., and Scofano Neto, F., Temperature-Dependent Viscosity Flow, in Convective Heat Transfer in Ducts: The Integral Transform Approach, eds. C. A. C. Santos, J. N. N. Quaresma, and J. A. Lima, Editora E-Papers, Rio de Janeiro, Brasil, 348 pp. 2001.

[29] Hunter, R. J., Recent Development in the Electroacoustic Characterization of Colloidal Suspension and Emulsions. Review, Colloid Surfaces A-Physicochemical Engineering Aspects, vol. 141, pp. 37-66, 1998.

[30] Hamilton, R. L., and Crosser, O. K., Thermal Conductivity of Heterogeneous Two-Component Systems, Industrial and Engineering Chemistry Fundamentals, vol. 1, pp. 187, 1962.

[31] Buongiorno, J., Venerus, D. C., Prabhat, N., Mckrell, T., Townsend, J., Christianson, R., et al., A Benchmark Study on the Thermal Conducitivity of Nanofluids, J. Applied Physics, vol. 106, p. 094312, 2009.

[32] Shah, R. K., Thermal Entry Solutions for the Circular Tube and Parallel Plates, Proc. of the 3rd National Heat and Mass Transfer Conf., vol. 1, Indian Institute of Technology, paper no. HMT-11-75, Bombay, India, 1975.

[33] Churchill, S. W., and Ozoe, H., Correlations for Laminar Forced Convection in Flow Over an Isothermal Flat Plate and in Developing and Fully Developed Flow in an Isothermal Tube, ASME Journal of Heat Transfer, vol. 95, pp. 416-423, 1973.

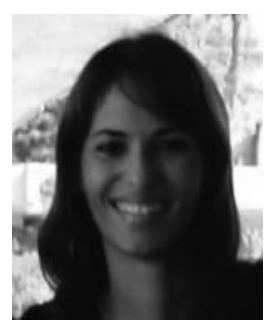

Ivana G. Cerqueira received her B.Sc. in mechanical engineering from the State University of Rio de Janeiro, Brazil, in 2008, and her M.Sc. in mechanical engineering from the Federal University of Rio de Janeiro in 2010, where she worked as a research assistant at the Laboratory of Transmission and Technology of Heat. Her M.Sc. thesis was devoted to the theoretical and experimental analysis of forced convection in laminar flow with nanofluids. She is presently a Ph.D. student in the Mechanical Engineering Department of the Federal University of Rio de Janeiro.

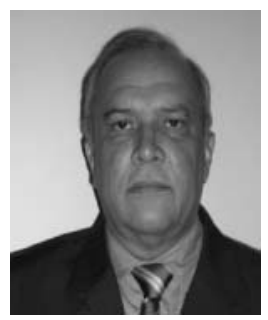

Carlos Alberto A. Mota is a senior analyst on science and technology of the National Council of Science and Technology-CNPq/Brazil. He received his doctoral degree in mechanical engineering from the Federal University of Rio de Janeiro in 2007. He has experience in mechanical and civil engineering, with emphasis on inverse problems and heat transfer.

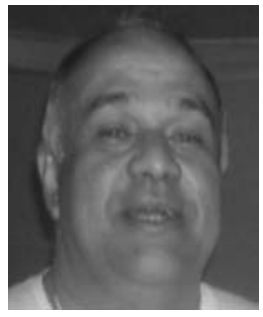

Jeziel S. Nunes holds a B.Sc. degree in mechanical engineering from PUC-RJ, Brazil (1982), a M.Sc. degree in mechanical engineering also from PUCRJ (1986), and the D.Sc. degree from the Federal University of Rio de Janeiro, COPPE/UFRJ, Brazil (2008). He has been a researcher on industrial property at INPI (National Institute of Industrial Property, Brazil) since 1985, and works on the Coordination of Programs and Studies of INPI since 2000.
$\mathrm{He}$ is also a permanent professor of the Intellectual Property and Innovation Academy of INPI. He has experience in teaching and research in intellectual property, mainly in the areas of technological information, patents, and technology transfer. He also works in research in the mechanical engineering field, with emphasis on the experimental analysis of heat and mass transfer at the microscale.

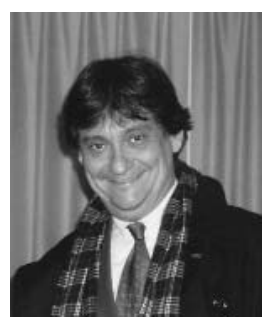

Renato M. Cotta received his B.Sc. on mechani$\mathrm{cal} /$ nuclear engineering from the Universidade Federal do Rio de Janeiro in 1981, and his Ph.D. in mechanical and aerospace engineering from North Carolina State University in 1985. In 1987 he joined the Mechanical Engineering Department at POLI \& COPPE/UFRJ, Universidade Federal do Rio de Janeiro, where he became a full professor in 1994 (COPPE) and in 1997 (POLI). He has authored about 410 technical papers and 5 books, and has supervised $29 \mathrm{Ph} . \mathrm{D}$. and $36 \mathrm{M} . \mathrm{Sc}$. students on their theses. He serves on the honorary editorial boards of several thermal sciences-related journals. He was also the editor-in-chief for the international journal Hybrid Methods in Engineering and is a regional editor of High Temperatures-High Pressures. He has contributed as elected president to the Brazilian Association of Mechanical Sciences, ABCM, in 2000-2001, to the Scientific Council of the International Centre for Heat and Mass Transfer since 1993, to the Executive Committee of ICHMT since 2006, and as head of the Heat Transmission and Technology Laboratory since 1994. $\mathrm{He}$ is an elected member of the National Honor Society of Phi Kappa Phi, USA (1984), recipient of the ICHMT Hartnett-Irvine Award 2010, and a full member of the National Engineering Academy, Brazil, and of the Brazilian Academy of Sciences.

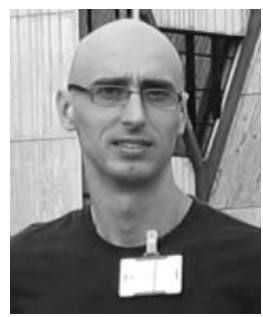

Andrea Balbo received his Ph.D. degree at the Faculty of Industrial Chemistry of the University of Bologna. From 2001 to 2006 he worked as a Research Assistant at the Institute CNR-ISTEC of Faenza (Italy), and, from 2006 to 2008, at the National Institute of Metrology, Standardization and Industrial Quality of Brazil (INMETRO) in the laboratory of thermal analysis and particulate systems. The research activity during this period focused on the characterization by thermal analysis of different classes of materials, on the development of nanofluids, and on characterization of their colloidal properties. Currently Dr. Balbo is a researcher at the Engineering Department of the University of Ferrara and his scientific activity involves the study of corrosion phenomena, their inhibition, and the development of new ceramic materials and metal matrix composites.

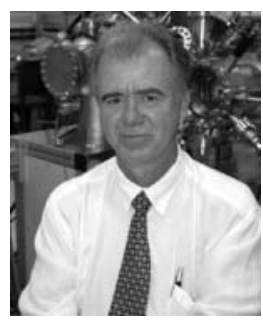

Carlos A. Achete received his D.Sc. in materials and metallurgical engineering from the Federal University of Rio de Janeiro in 1987. He is a full professor of the Instituto Alberto Luiz Coimbra de Pós Graduação e Pesquisa de Engenharia, COPPE/UFRJ, Universidade Federal do Rio de Janeiro, Brazil. Presently, he is licensed to work at INMETRO, National Institute of Metrology, Standardization and Industrial Quality of Brazil, where he serves as the Coordinator of Infrastructure and Laboratories and is head of the Materials Metrology Division. He maintains his academic position and teaching/advising activities at UFRJ. He has experience in physics, with emphasis on solids and liquids structure, and crystallography, with research on the more specific subjects of AFM, magnetron sputtering, hard thin films, plasma treatment, and interfaces and surfaces. 